\title{
EDUCAÇÃO ESCOLAR NA PERSPECTIVA DE ANTONIO GRAMSCI
}

\author{
School education in the perspective of Antonio Gramsci
}

Anderson Borges CORRÊA*

\begin{abstract}
RESUMO: Este trabalho tem o objetivo de problematizar o papel da educação escolar à luz do pensamento de Antonio Gramsci (1891-1937) e fazer uma discussão oportuna a este respeito considerando o atual estado da educação pública brasileira com base em avaliações de desempenho estudantil e algumas medidas de reestruturação, tendo em vista suas contradições e também princípios de Gramsci para uma educação popular. Uma revisão de literatura foi fundamental para discutir os principais conceitos que fundamentam este estudo, quais sejam: cultura, intelectuais orgânicos, escola única, educação humanista e ética na educação. A discussão conduz à elaboração de um pensamento a respeito da educação escolar pública com base em princípios educacionais, políticos e éticos para uma educação popular e humanista.
\end{abstract}

PALAVRAS-CHAVE: Educação escolar. Antonio Gramsci. Educação pública brasileira.

\begin{abstract}
Abstract: This paper aims to problematize the school educationrole in light of Antonio Gramsci's (18911937) thought and to carry out a timely discussion in this respect considering the current situation of Brazilian public education based on student development assessments and restructuring measures, regarding its contradictions and also Gramsci's principles to a popular education. A bibliographic review has been fundamental to discuss the main concepts that support this study, which are: culture, organic intellectuals, unitary school, humanist school and ethics in education. The discussion drives to a formulation of a thought in respect of public education based on educational, politics and ethics principles to a humanist and popular education.
\end{abstract}

KEYWORDS:: School education. Antonio Gramsci. Brazilian public school.

\section{Introdução}

Depois de 86 aniversários de criação do Ministério da Educação (MEC) no Brasil, o país ainda enfrenta uma situação alarmante em termos de resultados escolares de crianças e adolescentes que estudam na escola pública, fato corroborado pelos resultados do Índice de Desenvolvimento da Educação Básica (IDEB). As projeções das avaliações estudantis em

\footnotetext{
* Graduado em Letras pela Universidade Federal de Uberlândia - UFU; Especialista em Docência no Ensino Superior pela Faculdade Católica de Uberlândia; Mestrando em Educação pela Universidade de Uberaba UNIUBE; Professor de Informática Educativa na Rede Municipal de Ensino de Uberlândia: Secretaria Municipal de Educação - SME.
} 
relação aos anos iniciais do ensino fundamental apontam que das 27 unidades federativas, 18 não conseguirão cumprir a meta de nota 6 até 2021, valor estipulado pela Organização para a Cooperação e Desenvolvimento Econômico (OCDE) com base nas avaliações educacionais dos países desenvolvidos. Em relação aos anos finais do ensino fundamental, o número sobe para 21. Para o ensino médio, a projeção aponta que nenhuma federação deve atingir a meta no prazo estipulado. (BRASIL, 2016).

No Programa Internacional de Avaliação de Estudantes (PISA), os resultados apontam que "No Brasil, 51\% dos estudantes estão abaixo do nível 2 em leitura, patamar que a OCDE estabelece como necessário para que os jovens possam exercer plenamente sua cidadania" (BRASIL, 2016, p. 130). Para uma nação que ambiciona o desenvolvimento e a melhoria da qualidade de vida e educação há mais de 80 anos, este é um fato consideravelmente preocupante.

Dentre os planos de ação para elevar a qualidade da educação no Brasil, o governo federal, por meio do MEC, organizou uma proposta de Base Nacional Comum Curricular (BNCC) com consulta pública, envolvendo esforços de intelectuais das mais variadas regiões do país, para estabelecer uma base nacional curricular de conteúdos disciplinares como Arte, Educação Física, Ensino Religioso, Filosofia, Sociologia, Língua Estrangeira e outros.

Também, como proposta de governo, desta vez por parte da presidência do país, foi votada e decretada pelo Congresso Nacional a medida provisória de $\mathrm{n}^{\circ} 746$ que, dentre outros assuntos que altera, institui a política de implementação de escolas de Ensino Médio em tempo integral. Na redação final do documento, fica estabelecido que a formação de jovens no ensino médio tem o objetivo de promover o desenvolvimento "integral do aluno", voltado para a "construção de seu projeto de vida". (BRASIL, 2016, p. 4). Determina a 
obrigatoriedade do ensino de língua portuguesa e matemática nos três anos e torna facultativo aos sistemas de ensino a oferta de conteúdos como arte e educação física.

Ao arranjo curricular do Ensino Médio, fase final da educação básica, está integrada também a possibilidade de formação técnica e profissional, com "concessão de certificados intermediários de qualificação para o trabalho" (BRASIL, 2016), emitidos pelas próprias escolas.

Assim, em um cenário político e econômico de expectativas, sobretudo pela situação delicada de um governo presidencial provisório, a educação pública brasileira atualiza e reafirma seus propósitos construídos desde o Manifesto dos Pioneiros, isto é, o desejo de ocupar uma posição prioritária nas questões nacionais.

Em 2010, conforme declarou o então ministro de Estado da Educação, Fernando Haddad, no prefácio da obra Antonio Gramsci - uma publicação do MEC em parceria com a Fundação Nabuco -, a luta pela educação brasileira é atual e legítima. De acordo com ele,

[...] não será demais afirmar que o grande argumento do Manifesto de 1932, cuja reedição consta da presente Coleção, juntamente com o Manifesto de 1959, é de impressionante atualidade: "Na hierarquia dos problemas de uma nação, nenhum sobreleva em importância, ao da educação". Esse lema inspira e dá forças ao movimento de ideias e de ações a que hoje assistimos em todo o país para fazer da educação uma prioridade de estado. (HADDAD, 2010 apud MONASTA, 2010, p. 9).

Portanto, considerando o cenário da educação pública brasileira apresentado, este trabalho tem o propósito de problematizar o papel da educação escolar à luz do pensamento gramsciano por meio da seguinte indagação: Qual é o real papel da educação escolar pública? Tal questionamento deve levar à elaboração de um pensamento a respeito da educação escolar com base em princípios educacionais, políticos e éticos para uma educação popular humanista, nos termos definidos por Gramsci. Para isso, uma revisão de literatura foi fundamental para o estabelecimento dos principais conceitos que fundamentam esta 
discussão, quais sejam: cultura, intelectuais orgânicos, escola única, educação humanista e ética na educação

\section{Gramsci e suas influências no Brasil}

Nascido em uma das regiões mais pobres da Itália (Sardenha), Antonio Gramsci (1891-1937) teve a oportunidade de frequentar a Universidade por algum tempo. Trabalhando como jornalista e envolvido na organização sindical do Partido Socialista, e com a industrialização e a primeira Guerra Mundial, Gramsci se envolveu com a educação da classe operária emergente em Turim (MONASTA, 2010).

Monasta (2010) relata também que em razão de fazer parte da oposição do governo fascista Italiano, instaurado por Mussolini, Gramsci, assim como outros intelectuais parlamentares que representavam ameaça à ordem instaurada, foi condenado à prisão. No mesmo ano em que conseguiu liberdade total, sua morte foi anunciada: um acidente vascular cerebral.

Dez anos depois da morte de Gramsci (MONASTA, 2010), um momento oportuno, em que democratas e comunistas lideraram o governo italiano por algum tempo, favoreceu a popularização das ideias deixadas por ele acerca da história dos intelectuais e das dimensões educativa e política da educação popular.

No Brasil, desde a década de 1980, os escritos de Gramsci encontraram um terreno favorável ao amadurecimento de ideias revolucionárias a respeito da educação pública. Conforme relata Monasta (2010, p. 36), “Os textos de Gramsci arejaram nossa filosofia da educação que definitivamente incorporou a ideia de que a escola não se explica por ela própria e sim pela relação que mantém com a sociedade". Assim, as relações da educação com as dimensões social e política no Brasil ganharam força teórica, numa corrente contrahegemônica em favor da classe trabalhadora, à luz do pensamento gramsciano. 
No entanto, devido a falhas e interpretações “a-históricas” feitas de Gramsci no país, Monasta (2010, p. 40) adverte que "nossa leitura de Gramsci hoje" precisa ser "mais historicizada, mais contextualizada e mais datada", um cuidado compreensível e necessário para se evitar posições doutrinárias em relação a qualquer postulado teórico, além de pensamentos anacrônicos.

\section{Educação popular em Gramsci}

O acesso à cultura geral é o princípio essencial do processo de educação para qualquer ser humano, pois de acordo com Gramsci, ela, a cultura, é o que permite aos indivíduos percorrerem o caminho da crítica:

A cultura é uma coisa bem diversa. É organização, disciplina do próprio eu interior, é tomada de posse da própria personalidade, é conquista de consciência superior pela qual se consegue compreender o próprio valor histórico, a própria função na vida, os próprios direitos e os próprios deveres (GRAMSCI, 1976 apud MONASTA, 2010, p. $53)$.

Assim, é neste sentido que o autor afirma que a tomada de consciência dos indivíduos enquanto atores históricos implica esforço intelectual individual dentro de uma rede de relações sociais. Estas reflexões, segundo Gramsci, levam à tomada de consciência porque incidem sobre "a razão de certos fatos e sobre os meios considerados melhores para os converter de ocasião de vassalagem em insígnia de rebelião e de reconstrução social" (GRAMSCI, 1976 apud MONASTA, 2010, p. 53).

Resulta, portanto, que o eixo essencial da educação escolar na perspectiva de Gramsci, isto é, da educação popular, é oportunizar às crianças e jovens o acesso às máximas qualidades da cultura geral. Ao oportunizar acesso ao patrimônio humano historicamente produzido, a reflexão intelectual sobre determinados fatos leva à tomada de consciência da classe popular enquanto participantes deste fazer histórico e, portanto, dignos de outra 
condição social. Levando isso em consideração e a partir da perspectiva de uma educação popular, é discutível o fato de tornar obrigatórios no ensino médio apenas conteúdos disciplinares como língua portuguesa e matemática, ao mesmo tempo que componentes como arte e educação física permanecem facultativos.

Conforme sugere Gramsci, citado por Monasta (2010), a libertação da consciência é adquirida pela reflexão inteligente. No entanto, qualquer esforço intelectual deve ser historicamente situado. $\mathrm{O}$ autor afirma isso ao salientar a importância de o aprendiz experimentar a ânsia da busca pelo conhecimento, conhecendo o caminho percorrido que levou à descoberta. Ele explica:

Estamos persuadidos que uma verdade só é fecundada quando se fez um esforço para a conquistar, que ela não existe em si e para si, mas foi uma conquista do espírito, devendo reproduzir-se, em cada um, aquele estado de ânsia que atravessou o estudioso antes de a alcançar. Portanto, os professores dignos desse nome, no momento de educar, dão uma grande importância à história da matéria que se propõem ensinar. Este modo de apresentar aos ouvintes a série de esforços, os erros e vitórias pelos quais passaram os homens para alcançar o atual conhecimento, é muito mais educativo do que a exposição esquemática deste mesmo conhecimento (GRAMSCI, 1976 apud MONASTA, 2010, p. 62).

Portanto, conhecer o caminho histórico já percorrido para alcançar determinado conhecimento tem importância indispensável para um bom processo de ensino-aprendizagem na ótica de Gramsci. Ademais, situar historicamente qualquer conhecimento tem, inclusive, valor superior à mera exposição descontextualizada, seja na lousa ou em qualquer outro instrumento de exposição que se julgue mais moderno.

Assim, como se vê, o aprendiz atua como sujeito do próprio desenvolvimento e o profissional da educação assume papel fundamental neste processo, atuando como guia.

Em seus estudos sobre a história dos intelectuais, Gramsci considera os professores como intelectuais orgânicos. Sobre este tipo de intelectual ele afirma que: 
Pode-se observar que os intelectuais orgânicos que cada nova classe cria consigo e elabora em seu desenvolvimento progressivo são, na maioria dos casos, "especializações" de aspectos parciais da atividade primitiva do tipo social novo que a nova classe deu à luz. (GRAMSCI, 2001, p. 16).

Neste sentido, os docentes são intelectuais orgânicos por assumirem uma posição privilegiada numa atividade educativa de ampliação das capacidades intelectuais dos indivíduos, que integrarão uma nova classe. Gramsci (2001) ressalta a importância da ação destes intelectuais orgânicos mostrando que o trabalho de ampliação das capacidades intelectuais humanas, bem como de suas especializações, tem grande importância para o mundo moderno. Segundo ele, "Isso resulta das instituições escolares de graus diversos, até os organismos que visam a promover a chamada "alta cultura", em todos os campos da ciência e da técnica (GRAMSCI, 2001, p. 19).

Assim, os espaços escolares são lugares privilegiados de ampliação dos variados níveis de intelectualidade, bem como de suas especializações, em que professores e educadores assumem o papel de intelectuais orgânicos orientadores dos novos intelectuais em desenvolvimento: os alunos.

Deste modo, na perspectiva da educação popular, os resultados das avaliações sobre o desenvolvimento da leitura e da escrita pelas crianças e jovens, aspecto fundamental para a ampliação da intelectualidade, mostram que há necessidade de um plano de ação para reverter o atual cenário. Considerar que praticamente $50 \%$ das crianças e jovens têm grandes dificuldades para ler e escrever significa negar a ampliação da intelectualidade e as posteriores especializações. É negar que estas pessoas tenham oportunidades e condições para decidirem sobre suas próprias vidas, executarem seus próprios projetos de vida. É, sobretudo, negar a educação popular, humanista e de cultura geral. 
Como observa Gramsci (2001), o desenvolvimento de tais intelectuais por meio da educação escolar é influenciado fortemente pelas condições de acesso aos espaços de formação, aliadas às aspirações sociais. Um dos problemas apontados pelo autor em relação a isso é a educação em razão das funções do trabalho em detrimento da educação para a autonomia intelectual. Para Gramsci,este aspecto estava claro na Itália em relação à educação para a burguesia urbana e a educação para a burguesia rural.

Deve-se notar que a elaboração das camadas intelectuais na realidade concreta não ocorre num terreno democrático abstrato, mas segundo processos históricos tradicionais muito concretos. Formaram-se camadas que, tradicionalmente, "produzem" intelectuais; e elas são as mesmas que, com frequiência, especializaram-se na "poupança", isto é, a pequena e média burguesia fundiária e alguns estratos da pequena e média burguesia urbana. A diferente distribuição dos diversos tipos de escola (clássicas e profissionais) no território "econômico" e as diferentes aspirações das várias categorias destas camadas determinam, ou dão forma, à produção dos diferentes ramos de especialização intelectual (2001, p. 20).

Assim, conforme argumenta Gramsci (2001), diante da crise instaurada na educação devido aos diversos tipos de escolas - de acesso à cultura visando à autonomia intelectual e para o trabalho imediato -,havia uma nova necessidade de criação de um modelo de formação escolar geral, acessível a todos, para que, posteriormente, cada indivíduo tivesse condições de optar e prosseguir na atividade que lhe fosse interessante: universitária ou o trabalho. Ele define a escola única como um caminho para a autonomia intelectual:

Escola única inicial de cultura geral, humanista, formativa, que equilibre equanimente o desenvolvimento da capacidade de trabalhar manualmente (tecnicamente, industrialmente) e o desenvolvimento das capacidades do trabalho intelectual. Deste tipo de escola única, através de repetidas experiências de orientação profissional, passar-seá a uma das escolas especializadas ou ao trabalho produtivo (GRAMSCI, 2001, p. 33-34).

Desta forma, a educação popular, baseada nos princípios do humanismo, tem o compromisso de contribuir para que crianças e jovens se tornem capazes de decidir sobre suas 
próprias vidas, de fazerem as próprias escolhas e se posicionarem diante do mundo como sujeitos intelectuais de direitos e deveres. Portanto, a escola que Gramsci (2001, p. 32) chama de humanista, tem o objetivo de "desenvolver em cada indivíduo humano a cultura geral ainda indiferenciada, o poder fundamental de pensar e de saber orientar-se na vida".

De fato, é compreensível que uma escola nestes moldes valorize um currículo que contemple as máximas qualidades em relação à cultura geral. A mobilização governamental para o estabelecimento de uma base nacional de currículo comum pode ser vista como um esforço neste sentido. Por outro lado, uma medida provisória conivente, mesmo que pela omissão, com o impedimento de acesso dos estudantes a uma série de conhecimentos culturais historicamente construídos parece não estar alinhada a uma educação de princípios popular e humanista.

Para Gramsci (2001, p. 39), por meio do acesso à cultura em suas melhores qualidades é possível que se crie "a autodisciplina intelectual e a autonomia moral necessárias a uma posterior especialização, seja ela de caráter científico (estudos universitários), seja de caráter imediatamente prático-produtivo (indústria, burocracia, comércio, etc.)”. Desta forma, é compreensível que a educação popular propicie a ampliação intelectual dos sujeitos para que, dadas as condições para continuarem nas atividades que desejarem, eles dêem continuidade em seus projetos de vida.

Inevitavelmente, este pensamento de Gramsci entra em conflito com a medida provisória decretada pelo Congresso Nacional, que estabelece a formação técnica e profissional para o trabalho como possibilidade para a educação básica, no ensino médio. Para uma educação humanista, popular e preocupada com a ampliação intelectual dos sujeitos, e o posterior prosseguimento nos estudos ou no trabalho, é inviável que a formação para o trabalho se dê de forma adiantada. Este fato exemplifica de forma clara uma tendência de 
organização escolar já criticada por Gramsci: dois tipos de escolas, sendo as "clássicas" e as "profissionais", isto é, as escolas para a autonomia intelectual e aquelas voltadas para o trabalho.

Gramsci (2001, p. 39-40) defende que a escola popular, básica e de cultura geral, tenha suas bases nos princípios de uma escola "ativa" e "criadora", em que o aprendiz é sujeito do próprio processo de aprendizagem e o professor assume o papel de "guia amigável". Ele afirma que o trabalho escolar com atividades teórico-práticas é o caminho que leva à construção do conhecimento historicamente situado.

O conceito e o fato do trabalho (da atividade teórico-prática) é o princípio educativo imanente à escola elementar, já que a ordem social e estatal (direitos e deveres) é introduzida e identificada na ordem natural pelo trabalho. $\mathrm{O}$ conceito do equilíbrio entre ordem social e ordem natural com base no trabalho, na atividade teórico-prática do homem, cria os primeiros elementos de uma intuição do mundo liberta de toda magiaou bruxaria, e fornece o ponto de partida para o posterior desenvolvimento de uma concepção histórica, dialética, do mundo, para acompreensão do movimento e do devir, para a valorização da soma de esforços e de sacrifícios que o presente custou ao passado e que o futuro custa ao presente, para a concepção da atualidade como síntese do passado, de todas as gerações passadas, que se projeta nofuturo. (GRANSCI, 2001, p. 43).

Resulta pensar que, conforme sugere o autor, a atividade escolar comprometida com a ampliação intelectual dos sujeitos tem suas bases em princípios ativos e criadores, isto é, considera o aprendiz engajado em atividades teórico-práticas ao assumir-se como sujeito da própria aprendizagem, sob a orientação do professor.

Assim, conforme estabelece Gramsci (1976 apud MONASTA, 2010, p. 65-66), constituem-se princípios fundamentais para uma educação popular: (1) o acesso à cultura, independente da situação socioeconômica; (2) condições para o acesso às "escolas de cultura média e superior" para o prosseguimento dos estudos, se assim for desejado; e (3) "uma escola humanista", que possibilite a todas as crianças e jovens "todas as possibilidades, todos 
os terrenos livres para poder realizar sua própria individualidade do melhor modo possível, e por isso, de modo mais produtivo para eles mesmos e para a coletividade".

\section{Militância ética}

Tendo em vista a preocupação de Gramsci em garantir que estes princípios essenciais para uma educação popular fossem defendidos verdadeiramente, e não apenas dissolvidos em discursos aparentemente preocupados com o desenvolvimento intelectual de crianças e jovens em suas máximas potencialidades, Gramsci manifesta o desejo e a necessidade de assumir a postura de militância ética, acima de qualquer militância burocrática. (MONASTA, 2010).

Em relação a este desejo do pai, Giuliano, filho de Gramsci, deixa claro que, ainda nos anos 1930, Gramsci tinha a consciência de que a verdadeira militância a favor da classe trabalhadora era um grande desafio, devido à existência de militantes burocráticos, isto é, militantes apenas de discurso. Monasta cita Giuliano, o qual aponta que, para o pai, era necessário ultrapassar a burocracia e assumir uma postura de militância ética, verdadeiramente comprometida com a intelectualidade popular ea ascensão social.

meu pai - diz Giuliano - unia personagens politicamente diferentes, mas moralmente solidárias: Tatiana, Umberto Cosmo, Piero Sraffa, Pietro Gobetti... todos honestos antifascistas, mesmo que não fossem membros do Partido. Unia, ainda, Toscanini, Volterra, Croce, personagens cimentados por valores culturais, morais e até sentimentais que caracterizam a melhor tradição da cultura italiana. Esse conjunto de nomes configurava um clima cultural, uma frente moral e política superior ao Partido Burocrático. (1992 apud MONASTA, 2010, p. 45).

Estas palavras de Giuliano, traduzindo a postura ética e política do pai, levam a pensar que ética na educação escolar significa ir além das questões burocráticas e do discurso aparentemente comprometido; significa para os professores e educadores terem consciência do atual estado de hegemonia política, e, sobretudo, assumirem profissionalmente em sala de aula uma postura coerente com os princípios de uma educação verdadeiramente popular, isto 
é, de acesso à cultura geral e de abertura às possibilidades de desenvolvimento humano das mais sofisticadas habilidades

\section{Algumas considerações}

Como pôde ser percebido, o estado atual da educação pública brasileira é delicado e de muitas expectativas, conforme se revela por meio dos resultados de avaliações nacionais e internacionais e medidas de reestruturação do sistema educacional no país, sobretudo dos anos finais da educação básica.

Com base neste cenário, e na discussão de princípios da educação popular nos termos defendidos por Gramsci, é possível fazer algumas considerações, a fim de sistematizar um pensamento sobre o real papel da educação pública com base em princípios educacionais, políticos e éticos para uma educação popular e humanista.

Com base nas discussões sob a ótica da educação popular, a base de todo o processo educativo é o acesso das crianças e jovens às máximas qualidades da cultura geral, contextualizada historicamente no processo de ensino-aprendizagem. Isto significa defender a garantia de acesso na educação básica a todos os conteúdos disciplinares que possam contribuir para o desenvolvimento da liberdade e da autonomia intelectual, incluindo-se aí a arte, educação física, filosofia, sociologia, educação sobre o estado e a sociedade e outros.

Assumir tal postura significa ainda questionar a sistematização de formação técnica profissional para o trabalho ainda na educação básica, e reafirmar o compromisso de contribuir para que crianças e jovens tornem-se capazes de decidir sobre suas próprias vidas, de fazerem as próprias escolhas e se posicionarem diante do mundo como sujeitos intelectuais de direitos e deveres. Dadas estas condições, é perfeitamente possível que realizem, após a 
educação básica, seus próprios projetos de vida nas atividades que desejarem, na universidade ou no trabalho.

Os espaços escolares, na forma de lugares privilegiados de ampliação dos níveis de intelectualidade, bem como de suas especializações, constituem-se como lugares em que professores e educadores assumem o papel de intelectuais orgânicos orientadores dos novos intelectuais em desenvolvimento. Isso é possível porque, conforme sugere Gramsci (2001), a atividade escolar comprometida com a ampliação da intelectualidade tem suas bases em princípios ativos e criadores, isto é, considera o aprendiz engajado em atividades teóricopráticas ao assumir-se como sujeito da própria aprendizagem, sob a orientação do professor. Sendo assim, estas considerações ganham grande importância para a aprendizagem da escrita e da leitura, tão negligenciadas na educação pública do país.

Por fim, uma educação escolar verdadeiramente comprometida com os princípios de uma educação popular apenas pode ser sustentada por educadores e professores que assumam um posicionamento ético diante do compromisso com o desenvolvimento pleno de todas as crianças e jovens que estudam na escola pública.

É neste sentido que se compreende o papel da educação pública, pois dada a sua própria natureza e finalidade, ela precisa ser pensada e executada para atender a todos, de forma igualitária. Ademais, ao assumir a postura da escola popular de Gramsci, a escola pública se compromete em favorecer o acesso à cultura em suas máximas qualidades e propiciar o desenvolvimento das mais sofisticadas habilidades humanas, sob uma perspectiva de militância ética, em que os professores estejam conscientes do estado de hegemonia política e ativamente engajados na luta. 


\section{Referências Bibliográficas}

BRASIL. Brasil no PISA 2015: análises e reflexões sobre o desempenho dos estudantes brasileiros. OCDE - Organização para a Cooperação e Desenvolvimento Econômico. SãoPaulo : Fundação Santillana, 2016. In: Instituto Nacional de Estudos e Pesquisas Educacionais Anísio Teixeira. Brasília, 2001. Disponível em:

<http://portal.inep.gov.br/internacional-novo-pisa-resultados>. Acesso em: 28 de. 2016.

BRASIL. Estatísticas do Ideb 2015: Ensino Fundamental Regular e Ensino Médio Regular, 2016. In: Instituto Nacional de Estudos e Pesquisas Educacionais Anísio Teixeira. Brasília, 2001. Disponível em: <http://portal.inep.gov.br/web/portal-ideb/planilhas-para-download>. Acesso em: 28 de. 2016.

BRASIL. Medida provisória $n^{\circ} 746$, de 2016. Institui a Política de Fomento à Implementação de Escolas de Ensino Médio em Tempo Integral, altera a Lei n ${ }^{\circ}$ 9.394, de 20 de dezembro de 1996, que estabelece as diretrizes e bases da educação nacional, e a Lei no 11.494 de 20 de junho 2007, que regulamenta o Fundo de Manutenção e Desenvolvimento da Educação Básica e de Valorização dos Profissionais da Educação, e dá outras providências. Senado Federal, Brasília, dez. de 2016. Disponível em:

$<$ http://www.senado.leg.br/atividade/rotinas/materia/getPDF.asp?t=204698\&tp=1 >. Acesso em: 26 dez. 2016.

FORTUNATO, Sarita Aparecida de Oliveira. Escola, educação e trabalho na concepção de Antonio Gramsci. 2009. Disponível em:

<http://www.pucpr.br/eventos/educere/educere2009/anais/pdf/2015_2166.pdf >. Acesso em: 27 dez. 2016.

GRAMSCI, Antonio. Cadernos do cárcere. Os Intelectuais. O princípio educativo. Jornalismo. 2. ed.v. 2. Rio de Janeiro: Civilização Brasileira, 2001.

MONASTA, Attilio. Antonio Gramsci. Recife, PE: Massangana, 2010. 